\title{
Migraine in the post-menopausal period is associated with higher levels of mood disorders, disability, and more menopausal symptoms
}

\author{
Migrânea no período pós-menopausal se associa a maiores índices de alterações do \\ humor, de incapacidade e de sintomas de menopausa
}

Paula Carturan 1 , Claudio Scorcine ${ }^{2}$, Yara Dadalti Fragoso 3

\begin{abstract}
Objective: To assess the prevalence of headache in post-menopausal women. Methods: Women attending gynecology outpatient services in the coastal region of the state of Sao Paulo, Brazil were invited to participate in this study. Only those with non-surgical menopause and no hormone replacement therapy were included. Prevalence and characterization of headaches were assessed, as well as the burden of migraine, traits of anxiety and depression, and menopausal symptomatology. Results: One hundred and three women were included in the study. Migraine affected $14.7 \%$ of them. Some previous type of headache was reported by $86.2 \%$ of the women, most of whom improved during menopause but still presented with headache attacks. There was a correlation between higher migraine disability and depressive traits. Conclusions: Many women believe that their headaches, particularly migraine, will end after menopause. This is, unfortunately, not the case for many of them.
\end{abstract}

Keywords: headache; migraine disorders; menopause; women.

\section{RESUMO}

Objetivo: Avaliar a prevalência de cefaleia em mulheres no período pós-menopausal. Métodos: Mulheres atendidas em serviços de ginecologia na região costeira do estado de São Paulo, Brasil foram convidadas a participar deste estudo. Apenas mulheres com menopausa não-cirúrgica e sem terapia de reposição hormonal foram incluídas. Foram avaliados prevalência e características das cefaleias, incapacidade por enxaqueca, traços de ansiedade e depressão e sintomatologia menopausal. Resultados: Centro e três mulheres foram incluídas neste estudo. Enxaqueca afetava 14,7\% delas. Antecedente de algum tipo de dor de cabeça foi relatada por 86,2\% das mulheres, a maioria das quais melhorou durante a menopausa, mas ainda apresentava crises. Houve correlação entre maior incapacidade por enxaqueca e traço depressivo. Conclusão: Muitas mulheres acreditam que suas cefaleias, particularmente enxaqueca, terminarão quando começar a menopausa. Este, infelizmente, não é o caso para muitas delas.

Palavras chave: cefaleia; transtornos de enxaqueca; menopausa; mulheres.

The reproductive lifecycle of women with migraine has always been a subject of interest ${ }^{1}$. The menarche, menses, pregnancy, post-natal and menopausal periods are all associated with different degrees and frequency of migraine ${ }^{2}$. While there is a lay concept that migraine will improve after the menopause, this is unfortunately not true. Migraine is a multifactorial disorder and it would be very simplistic to consider it to be related exclusively to hormonal cycles. Headache clinics, particularly within tertiary care, receive many women whose migraines have not improved, have worsened or have even started after menopause. Hormonal replacement therapy does not seem to be a good therapeutic option for all women, since many of them report worsening of their migraine after starting hormone replacement.

A very recent systematic review on the subject of migraine and menopause ${ }^{3}$ identified 22 relevant studies showing that migraine is reported by $10 \%$ to $29 \%$ of menopausal women. The authors of the systematic review concluded that migraine prevalence remains stable or increases after the menopause. While population-based studies showed a tendency towards

1 Universidade Metropolitana de Santos, Departamento de Ginecologia e Obstetrícia, Santos SP, Brasil;

${ }^{2}$ Universidade Metropolitana de Santos, Faculdade de Educação Física, Santos SP, Brasil;

${ }^{3}$ Universidade Metropolitana de Santos, Departamento de Neurologia, Santos SP, Brasil.

Correspondence: Yara Dadalti Fragoso; Departamento de Neurologia da Faculdade de Medicina da UNIMES; Rua da Constituição, 374 ; 11015 -470 Santos SP, Brasil; E-mail:yara@bsnet.com.br

Conflict of interest: There is no conflict of interest to declare.

Received 05 June 2016; Received in final form 01 September 2016; Accepted 14 September 2016. 
less severe migraines after menopause, data from tertiary clinics showed stable or worse migraine attacks after menopause $^{3}$. In the same review, the authors identified only three papers addressing perimenopausal symptomatology and the results were not uniform. One study with over 700 patients from a headache clinic showed no clear relationship between migraine and the menopause syndrome ${ }^{4}$. A population-based longitudinal study showed that it was only during the menopausal transition that a clear pattern of migraine and menopausal symptoms could be observed ${ }^{5}$. A very large population-based longitudinal cohort showed that, in fact, perimenopausal symptomatology seems to be determined by multifactorial aspects of socioeconomic, demographic, reproductive and lifestyle parameters among these women ${ }^{6}$. The present study reports on mood disorders, menopausal symptoms and labor disability in menopausal women.

\section{METHODS}

The project was approved by the Ethics Committee of Universidade Metropolitana de Santos, under the number CAAE 46032715700005509. Confidentiality was guaranteed for the patients, who signed a statement consenting to voluntary participation in the study of the menopausal syndrome. The aim of the study (assessment of primary headaches) was not disclosed at this point, in order to avoid bias in the selection of patients.

Menopausal patients attending public gynecological outpatient healthcare services in Santos, Sao Vicente, Praia Grande and Cubatão (all of which are cities in the coastal region of the State of Sao Paulo, Brazil) were invited to take part in this project. The critical inclusion criteria were that the patients needed to present with a natural (non-surgical) menopause, without having had hormone replacement therapy at any time (their own choice). Those who fulfilled these criteria and were willing to participate were interviewed individually. The interview focused on the presence and characteristics of headaches at any time in their lives (primary outcome). Regarding secondary outcomes, all participants were screened for anxiety and/or depression traits using the Hospital Anxiety and Depression Scale ${ }^{7}$ and for the menopause syndrome by means of the Menopause Rating Scale ${ }^{8}$. This scale takes into account many aspects of menopausal symptoms such as cognition, mood disorders, worries, quality of sleep, pain, urogenital complaints and sexual satisfaction. Socioeconomic level was assessed using the Brazilian rating system from the Instituto Brasileiro de Geografia e Estatística. According to this system, socioeconomic classes range from $\mathrm{A} 1$ (highest) to $\mathrm{E}$ (lowest).

Depending on the characterization of the headache, the patients were divided into three groups: no headache, migraine, and other headache (non-migraine). The diagnosis of migraine was obtained in accordance with the criteria from the International Headache Society ${ }^{9}$ and these patients answered the Migraine Disability Assessment (MIDAS) questionnaire ${ }^{10}$, which has been validated in Brazil ${ }^{11}$. The MIDAS questionnaire establishes the degree of disability and treatment requirements for migraine over the last three-month period. The effect of migraine on disability and the urgency of adequate treatment can be scored as mild, moderate or severe.

Statistical analyses were performed blindly, and variables were analyzed by means of the Mann Whitney test for comparison of the three groups regarding headache pre- and post-menopause, anxiety and depression, menopausal symptoms and socioeconomic level. Spearman's correlation test and ANOVA were used for assessing the potential correlation among values for MIDAS, menopause symptoms, anxiety and/or depressive traits. A 95\% confidence interval was established and values were considered to be significant if $\mathrm{p}<0.05$. Sample size calculation established $\mathrm{n}=88$ for this population of patients.

\section{RESULTS}

One hundred and three women attending gynecology outpatient services in connection with menopause, in cities of the coastal region of the State of Sao Paulo, agreed to take part in this survey. The average age of these patients was $54.2 \pm 3.0$ years, and the average period that had elapsed since the last menstrual period was $7.0 \pm 4.5$ years. The socioeconomic level of this population attending public healthcare services ranged from $\mathrm{A}$ to $\mathrm{D}$, and was, on average, classified as $\mathrm{C} 1$, which is representative of the Brazilian population as a whole.

From the whole group of menopausal women, $86.2 \%$ reported a history of some type of headache [tension type headache (71.8\%), unclassifiable facial or cranial pain (9.7\%)], and $14.7 \%$ had migraine 9 . Demographic data on the patients in the three groups (migraine, non-migraine headache and no headache) are presented in Table 1. In summary, there were no significant differences regarding the patients' ages, time elapsed since menopause and socioeconomic classes among the groups. After menopause, $61.8 \%$ of the patients did not have any change to, or improvement of, their headaches, while $38.2 \%$ of them had worse headaches.

The length of time for which the menopausal women with migraine had been presenting with this was 23 years, and none presented with headache starting at or after menopause. However, $39 \%$ of the patients reported worsening of migraine after the last menstrual period ( $\mathrm{p}=0.05)$. Regarding frequency of migraine, $28.6 \%$ of the women reported having two or more attacks per month, and $3.8 \%$ of these presented with chronic migraine with more than 15 days of pain per month.

Data on the patients with migraine are presented in Table 2 . The disability due to migraine was considered mild in $66.7 \%$ of the women, moderate in $26.7 \%$ and severe in 
$6.6 \%$. The women with migraine had significantly higher levels of anxiety and depressive traits $(p=0.01)$, as well as more menopausal symptoms $(p=0.00)$. There were no significant differences regarding socioeconomic levels among the patients in the three groups. It is interesting to notice that the women with other forms of headache (non-migraine) had intermediate levels of anxiety, depression and menopausal symptoms, in comparison with the migraine patients and the controls without any headache. These data are summarized in Table 1.

Disability caused by migraine is summarized in Table 2 . One third of the patients with migraine required adequate management and therapy, as shown through MIDAS. The MIDAS score was correlated with the score for depressive traits ( $p=0.01$ ). The MIDAS questionnaire is specific for assessing migraine burden and, therefore, was not used to assess the burden of non-migraine headaches in this study.

\section{DISCUSSION}

Menopause is a period of great changes to women's bodies and minds. Alterations to body image and emotions, psychological adjustment to a new phase of life and worries about the higher prevalence of severe diseases and cognitive dysfunction all contribute towards negatively affecting the quality of life of menopausal patients ${ }^{12,13}$. Symptoms that are typical of hormonal deprivation and aging are prevalent and distressful to many, often requiring individual counseling and specific therapies ${ }^{14}$. Some of the symptoms are manageable and headache is certainly a modifiable parameter if given the appropriate treatment. In the present series, about one third of the women had experienced worsening of their primary headaches after their last menstrual period, which contradicts the popular belief that "after menopause the headache gets better".

Many women believe that the burden of their migraine will finish at menopause but this is, unfortunately, not the case for many. In the present study, the prevalence of migraine after menopause was similar to that found by other authors ${ }^{3}$ and nearly a quarter of the postmenopausal women in our series had migraine attacks. This result is in agreement with a recent expert consensus on the matter ${ }^{15}$. The majority of the cases of migraine in this series did not show severe disability. However, the results from MIDAS point towards the fact that the lives of a considerable number of women are disrupted by the burden of migraine, resulting in missing days of work, housework and leisure time due to their headache attacks. The MIDAS values, in this population, are similar to that of Brazil as a whole ${ }^{16}$. Higher levels of anxiety, depressive traits, menopause symptomatology and intensity of headache pain in attacks were all significant for post-menopausal women with migraine.

There are limitations to the present work, particularly due to the relatively small population of women with migraine assessed here. However, the prevalence of migraine found in the patients enrolled in this study is in accordance with the literature ${ }^{3,16}$ and the increased symptomatology is also in line with a recent systematic review of the subject ${ }^{3}$. Therefore, even if the final number of women with migraine in the study is not high, they seem to be representative of this population of patients. In addition, another limitation to the study was the short follow-up of these menopausal women, in the order of seven years on average. Women may

Table 1. Characteristics of patients without headache, with non-migraine headache and with migraine after menopause.

\begin{tabular}{|c|c|c|c|c|c|c|c|c|}
\hline \multirow[t]{2}{*}{ Variable } & \multirow[t]{2}{*}{$\mathrm{N}$} & \multirow[t]{2}{*}{$\%$} & \multirow[t]{2}{*}{$\begin{array}{c}\text { Age at } \\
\text { menopause }\end{array}$} & \multirow[t]{2}{*}{ Present age } & $\begin{array}{c}\text { Worsening } \\
\text { of headache } \\
\text { after } \\
\text { menopause }\end{array}$ & Anxiety trait & $\begin{array}{c}\text { Depression } \\
\text { trait }\end{array}$ & \multirow[t]{2}{*}{$\begin{array}{l}\text { Hauser } \\
\text { (average) }\end{array}$} \\
\hline & & & & & $\mathrm{n}(\%)$ & n (\%) & n (\%) & \\
\hline Total group of patients & 103 & - & $46.7 \pm 5.0$ & $51.2 \pm 3.1$ & $33(38.2)$ & $23(22.3)$ & $11(10.7)$ & $4.9 \pm 1.8$ \\
\hline No headache & 14 & 13,5 & $45.7 \pm 4.9$ & $53.3 \pm 3.1$ & - & $1(7.1)$ & 0 & $4.5 \pm 1.3$ \\
\hline Non-migraine headache & 74 & 71,8 & $47.6 \pm 4.4$ & $54.4 \pm 3.0$ & $27(26.5)$ & $15(20.3)$ & $8(10.8)$ & $4.9 \pm 1.8$ \\
\hline Migraine & 15 & 14,7 & $44.8 \pm 6.0$ & $53.5 \pm 3.5$ & $6(40)$ & $7(46.6)$ & $3(20)$ & $5.5 \pm 2.5$ \\
\hline
\end{tabular}

Table 2. Results of disability caused by Migraine Disability Assessment ${ }^{10,11}$. There were 15 patients with migraine (out of 103 women) in this study.

\begin{tabular}{lcccc}
\hline MIDAS & Disability & Therapy & Number of patients & Percentage \\
\hline 0 to 5 & Minimal & Smal or no need & 6 & $40.0 \%$ \\
6 to 10 & Mild or infrequent & Moderate need & 4 & $26.7 \%$ \\
11 to 20 & Moderate & Requires & 4 & $26.7 \%$ \\
$>21$ & Severe & Requires urgent & 1 & $6.6 \%$ \\
\hline
\end{tabular}


live a third of their lives in the post-menopausal period and different stages of this condition should be assessed as well. It is possible that, after 20 or 25 years of menopause, women may show different findings to these reported here. Further studies should address the methodological pitfalls of the present study.
In conclusion, in a population of women with natural non-surgical menopause and without hormone therapy replacement, the burden of migraine often persists after menopause. Other associated psychiatric and gynecological symptoms increase the disability in these women. These factors are potentially modifiable.

\section{References}

1. Brandes JL. Migraine in women. Continuum (Minneap Minn). 2012;18(4):835-52. doi:10.1212/01.CON.0000418646.70149.71

2. Chai NC, Peterlin BL, Calhoun AH. Migraine and estrogen. Curr Opin Neurol. 2014;27(3):315-24. doi:10.1097/WC0.0000000000000091

3. Ripa P, Ornello R, Degan D, Tiseo C, Stewart J, Pistoia F et al. Migraine in menopausal women: a systematic review. Int J Womens Health. 2015;7:773-82. doi:10.2147/IJWH.S70073

4. Mattsson P. Hormonal factors in migraine: a population-based study of women aged 40 to 74 years. Headache. 2003;43(1):27-35. doi:10.1046/j.1526-4610.2003.03005.x

5. Freeman EW, Sammel MD, Lin H, Gracia CR, Kapoor S. Symptoms in the menopausal transition: hormone and behavioral correlates. Obstet Gynecol. 2008;111(1):127-36. doi:10.1097/01.AOG.0000295867.06184.b1

6. Sabia S, Fournier A, Mesrine S, Boutron-Ruault MC, Clavel-Chapelon F. Risk factors for onset of menopausal symptoms: results from a large cohort study. Maturitas. 2008;60(2):108-21. doi:10.1016/j.maturitas.2008.04.004

7. Zigmond AS, Snaith RP. The hospital anxiety and depression scale. Acta Psychiatr Scand. 1983;67(6):361-70. doi:10.1111/j.1600-0447.1983.tb09716.x

8. Hauser GA, Huber IC, Keller PJ, Lauritzen C, Schneider HP. [Evaluation of climacteric symptoms (Menopause Rating Scale)[. Zentralbl Gynakol. 1994;116:16-23. German.
9. International Headache Society. The international classification of headache disorders. 2nd ed. London: International Headache Society; 2004. Cephalalgia. Suppl 1:9-160.

10. Lipton RB, Stewart WF, Sawyer J, Edmeads JG. Clinical utility of an instrument assessing migraine disability: the Migraine Disability Assessment (MIDAS) questionnaire. Headache. 2001;41(9):854-61. doi:10.1046/j.1526-4610.2001.01156.x

11. Fragoso YD. MIDAS (Migraine Disability Assessment): a valuable tool for work-site identification of migraine in workers in Brazil. Sao Paulo Med J. 2002;120(4):118-21. doi:10.1590/S1516-31802002000400006

12. Banister EM. Women's midlife confusion: "why am I feeling this way?" Issues Ment Health Nurs. 2000;21(8):745-64. doi:10.1080/016128400750044251

13. Pearce G, Thøgersen-Ntoumani C, Duda J. Body image during the menopausal transition: a systematic scoping review. Health Psychol Rev. 2014;8(4):473-89. doi:10.1080/17437199.2013.848408

14. Reid R, Abramson BL, Blake J, Desindes S, Dodin S, Johnston S et al. Managing menopause. J Obstet Gynaecol Can. 2014;36(9):830-8. doi:10.1016/S1701-2163(15)30487-4

15. Bordini CA, Roesler C, Carvalho DS, Macedo DDP, Piovesan E, Melhado EM, et al. Recommendations for the treatment of migraine attacks: a Brazilian consensus. Arq Neuropsiquiatr 2016;74(3):262-71. doi:10.1590/0004-282X2015021

16. Queiroz LP, Silva Junior A. The prevalence and impact of headache in Brazil. Headache. 2015;55 Suppl 1:32-38. doi:10.1111/head.12511 